\title{
Prenatal dilatation of the pulmonary artery in the third trimester - important information for paediatric cardiologist or for neonatologist? Case report
}

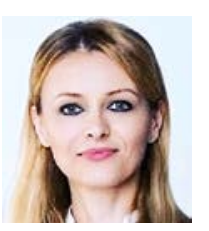

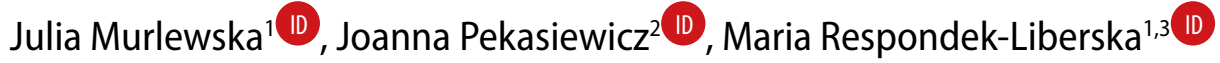 \\ 'Department of Prenatal Cardiology, Polish Mother's Memorial Hospital, Lodz, Poland \\ ${ }^{2}$ Student of Medical Faculty, Medical University of Lodz, Poland \\ ${ }^{3}$ Department for Congenital Malformations and Prevention, Faculty of Public Health, Medical University of Lodz, Poland
}

\begin{abstract}
We present a case of dilated main pulmonary artery diameter with accompanying cardiac anomalies and postnatal follow-up. The abnormalities in the left side of the heart concerned the left superior vena cava (LSVC), decreased left ventricular contractility SF LV (shortening fraction), and narrowing/accelerating flows through the aortic valve and aortic arch isthmus. In our case, coarctation of the aorta was suspected both pre- and postnatally due to the dominant picture of the accelerated flow velocities, but the patient did not require neonatal surgery. Based on a retrospective review of the case, we tried to explain our prenatal and early postnatal findings. After the exclusion of the structural congenital heart defects as a base of the dilatation of the main pulmonary artery, we should consider other pathophysiological mechanisms presented in the following report.
\end{abstract}

Key words: dilated pulmonary artery, coarctation of the aorta, false-positive CoA, case study, third trimester, prenatal cardiology, fetal echocardiography, fetal echo, prenatal diagnosis, differential diagnosis.

\section{Introduction}

The broad pulmonary trunk in the third trimester of gestational age should be given special attention in the context of predicting the postnatal compromise and the assessment of cardiopulmonary efficiency of newborns [1-9]. An intrauterine environment, an in-utero infection, and fetal pulmonary hypertension can contribute to abnormal prenatal echocardiographic findings and may predict abnormal newborns' adaptation to ex-utero life [1-9].

\section{Corresponding author:}

Dr. Julia Murlewska

Department of Prenatal Cardiology

Polish Mother's Memorial Hospital Research Centre

Lodz, Poland

e-mail: juliamurlewska.jm@gmail.com

We present a case of dilated main pulmonary artery diameter (up to $13 \mathrm{~mm}$ ) with accompanying cardiac anomalies and postnatal follow-up.

\section{Case report}

A pregnant woman, G3P2, with positive medical reconnaissance for a right bundle branch block was directed to the Fetal Cardiology Centre in the $3^{\text {rd }}$ Reference Hospital due to suspected heart defect of a fetus. The abnormalities concerning disproportions at the level of four cardiac chambers and 


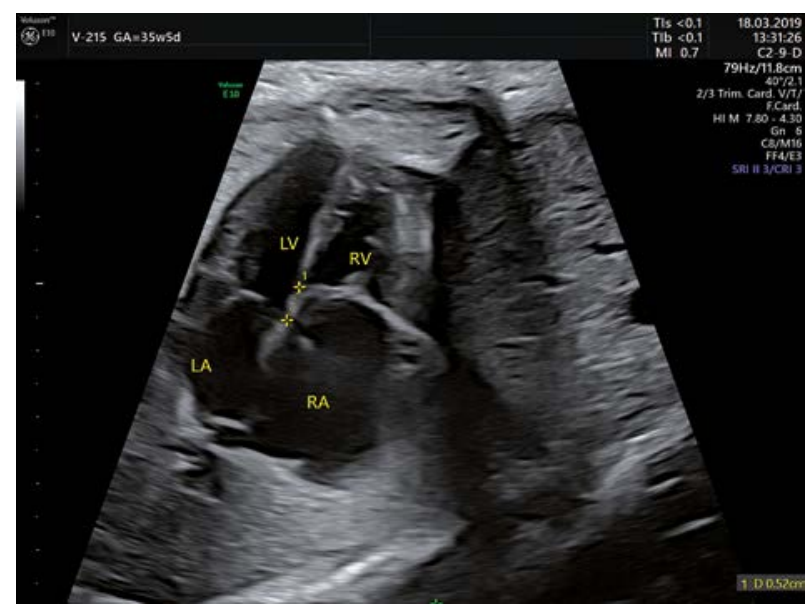

Figure 1. 4CV disproportion, dysplastic TV, 36 weeks of pregnancy, MDTmitral valve-tricuspid valve distance $5.2 \mathrm{~mm}$ dysplastic TV

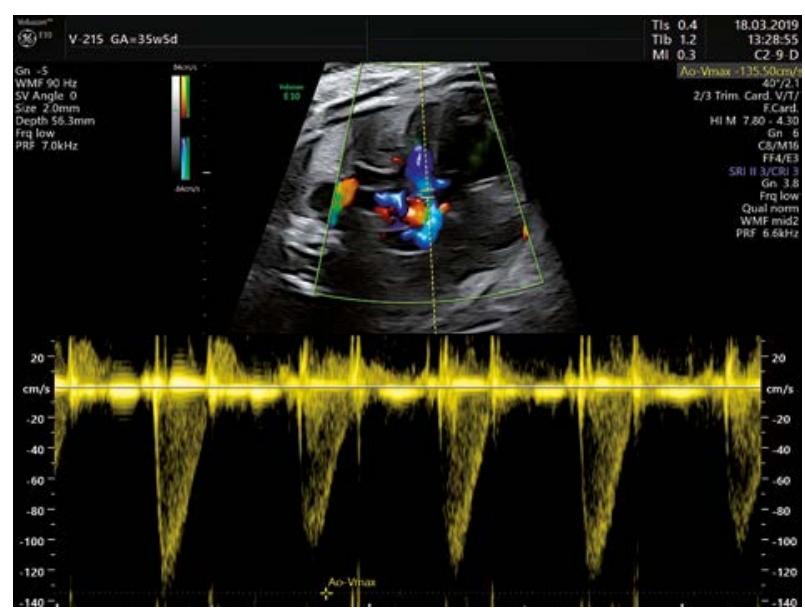

Figure 3. Increased AoV vel flow, 36 weeks, due to CoA?

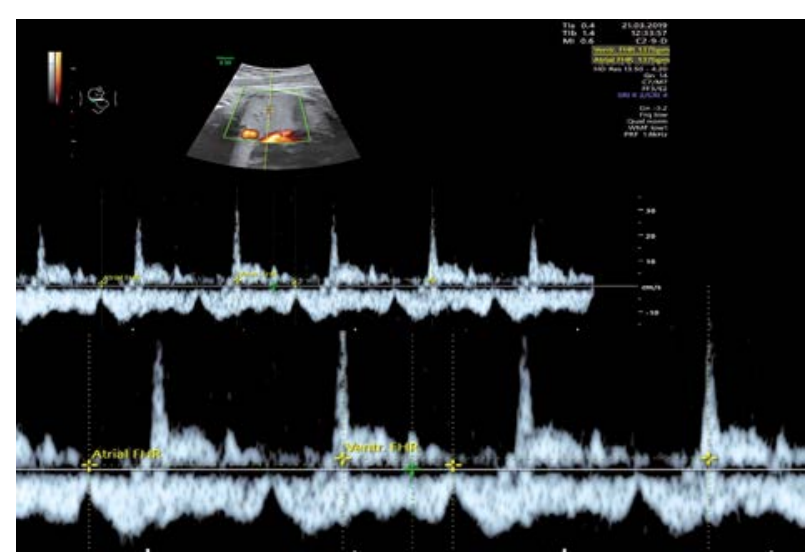

Figure 5. PVs flows, FHR ventricles $=$ FHR atria $=137 \mathrm{bpm}, 36$ weeks

three vessels of the upper mediastinum were detected at the $21^{\text {st }}$ week of the pregnancy. The first specialised echocardiographic examination in the tertiary centre in our hospital took place at the $36^{\text {th }}$ week. Then, attention was paid to the dominance of the right side of the heart (Figure 1), with a broad pulmonary trunk main pulmonary artery diameter (MPA dia)

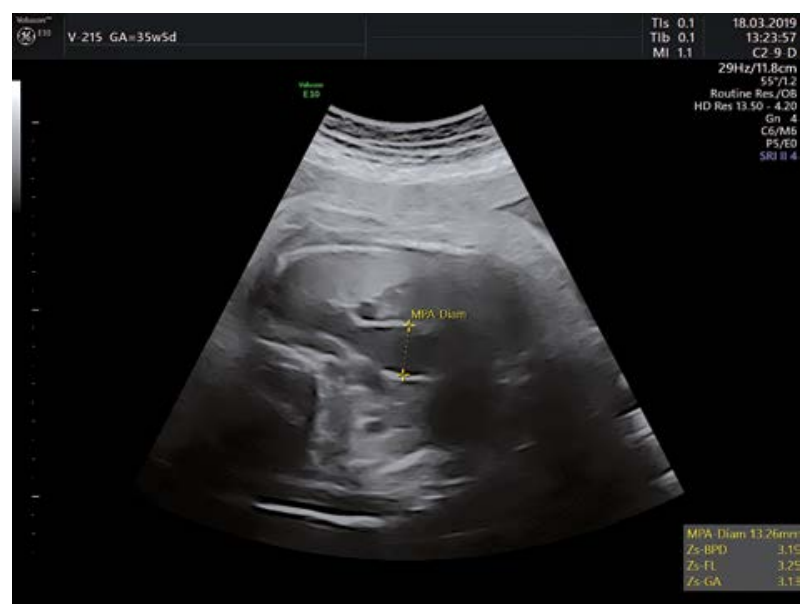

Figure 2. Dilatation of MPA at $36 \mathrm{GA}$ as a predictor of heart defect or persistent pulmonary hypertension? In mediastinum there are 4 vessels (bilateral SVC, narrow aorta, and good size of the thymus)

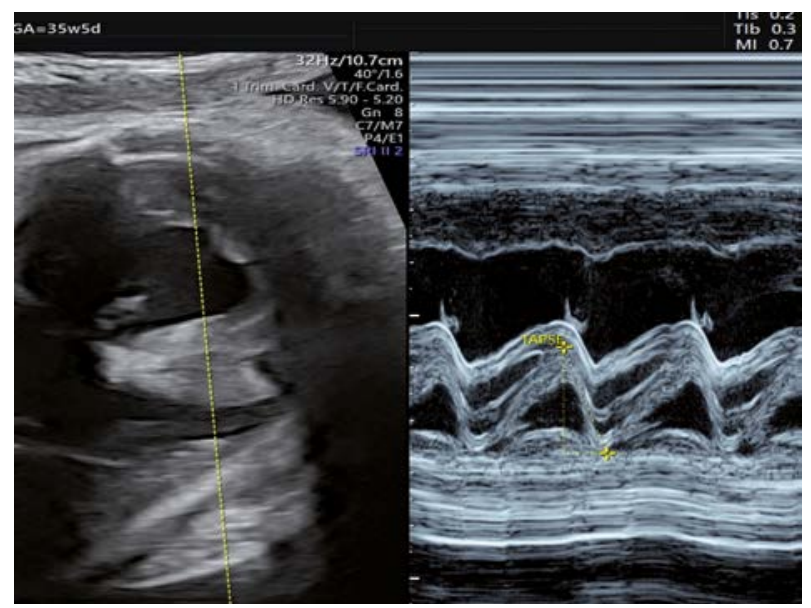

Figure 4. Increased TAPSE measurement at 36 weeks of pregnancy due to dysplastic TV?

of $13 \mathrm{~mm}$, Z-score of +3.13 for gestational age (GA) (Figure 2), and narrow branches of the pulmonary trunk, as well as to the difference between dimensions of the atria and ventricles $>2 \mathrm{~mm}$, without signs of cardiomegaly heart area/chest area $(\mathrm{HA} / \mathrm{CA})=0.35$.

The abnormalities in the left side of the heart concerned the left superior vena cava (LSVC), decreased left ventricular contractility SF LV $=23 \%$ (shortening fraction), and narrowing/accelerating flows through the aortic valve and aortic arch isthmus. The maximum flow velocities through the aortic valve amounted to $135.5 \mathrm{~cm} / \mathrm{s}$ (Figure 3), via ductus arteriosus/aortic isthmus (DA/Aol) $156 \mathrm{~cm} / \mathrm{s}$ prenatally. The distance between the mitral valve (MV) and tricuspid valve (TV) insertion to the interventricular septum (IVS) exceeded $5 \mathrm{~mm}$. The tricuspid annular plane systolic excursion (TAPSE) rate was significantly elevated, at $14 \mathrm{~mm}$. The tricuspid valve was assessed as dysplastic (Figure 4).

The venous pulmonary flows were accelerated, $\mathrm{v}_{\max } 46 \mathrm{~cm} / \mathrm{s}$, while the ventricular and atrial heart function were compatible $\mathrm{FHR}=137 \mathrm{bpm}$ (Figure 5) and ventricular-atrial conduction time was extended (PR interval $=169 \mathrm{~ms})$. The assessment of 
the fetal circulatory compromise in the cardiovascular scale CVPS amounted to $9 / 10$ points ( -1 for SF LV) (Table 1 ).

Except for the cardiac abnormalities, hydrops testis and fetus large for gestational age (LGA) were diagnosed; LGA: $35 \mathrm{w} 5 \mathrm{~d} / 38 \mathrm{w} 4 \mathrm{~d}-3502 \pm 511 \mathrm{~g}$. AFI was $16 \mathrm{~mm}$. Placental thickness was $33 \mathrm{~mm}$. Based on prenatal findings of reactive hydrocele, prenatal antibiotic vaginal therapy was proposed in the end stage of pregnancy. The spontaneous delivery took place seven days after the echocardiography at the $37^{\text {th }}$ week of the pregnancy. The newborn had a birth weight of $3700 \mathrm{~g}$, Apgar 7,8 . Assuming prenatal coarctation of the aortae as a ductaldependent lesion, Prostin was given for 12 days (doses from 0.02 to $0.01 \mathrm{mg} / \mathrm{kg} / \mathrm{min}$ ).

Postnatal echocardiographic examination and 3D angio-CT examinations (Figures 6, 7) revealed narrowing of the mitral valve, and mild MV stenosis with incorrect histogram up to $1.4 \mathrm{~m} / \mathrm{s}$ (mean PG $-3 \mathrm{~mm} \mathrm{Hg}$ ). The presence of LSVC, tricuspid valve with elongated leaflets, characterised with the dysplasia and with signs of regurgitation and valvular cusp prolapse with difficult visualisation of the posterior leaflet were described. There was a high located intramembranous ventricular septal defect of about $2 \mathrm{~mm}$ and narrowing of the aortic isthmus of about $3 \mathrm{~mm}$ with colour Doppler flow velocity up to $2.45 \mathrm{~m} / \mathrm{s}$ (PG - $24 \mathrm{~mm} \mathrm{Hg}$ ). During the hospitalisation period, the reduction percentage of the $\mathrm{N}$-terminal brain natriuretic peptide (NTproBNT), which predicts long-term mortality and readmission in heart failure patients, was seen.

In the next control postnatal echocardiograms (in the first two weeks of the newborn's life) no escalating gradient in the aortic isthmus was observed. Laboratory findings confirmed neonatal infection, and antibiotic therapy with gentamicin and ampicillin was given for two weeks. The total hospitalisation time amounted to 30 days, including 17 days at the Neonatal Intensive Care Clinic. The newborn was not qualified for cardiosurgery and was discharged after long-term pharmacological treatment (as mentioned before) and recommendations to attend a further Cardiology Outpatient Clinic.

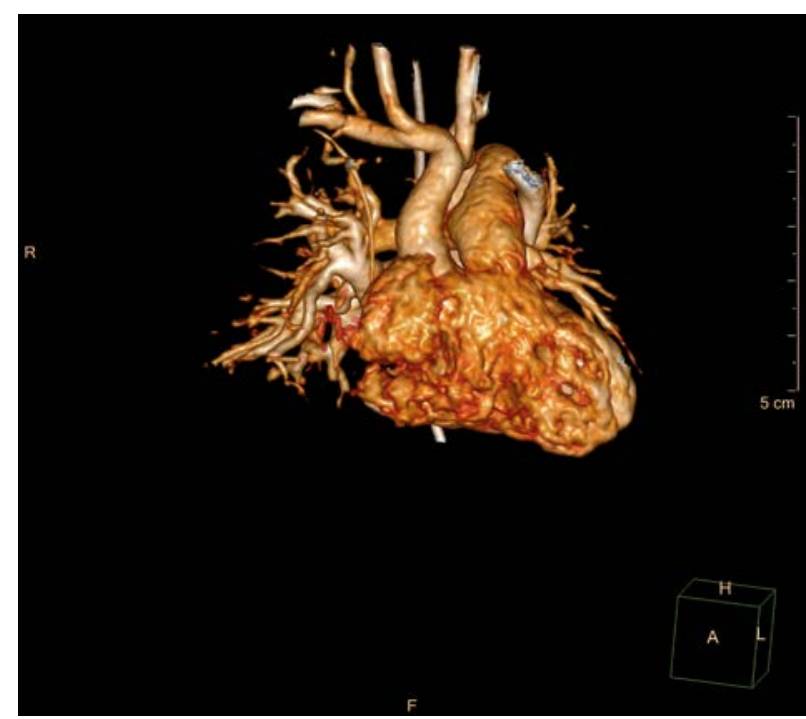

Figure 6. Angio (T, newborn: a picture of the coarctative nature of the isthmic segment (Aol $3 \mathrm{~mm}, \mathrm{v}_{\max } 245 \mathrm{~cm} / \mathrm{s}$ )
Table 1. Prenatal echocardiographic parameters

\begin{tabular}{|l|c|}
\hline Parameters & Results \\
\hline GA LMP & 35.5 \\
\hline GA US & 38.4 \\
\hline HA/CA & 0.35 \\
\hline AP [mm] & 42 \\
\hline LV SF [\%] & 23 \\
\hline TAPSE & 14 \\
\hline MAPSE & 5 \\
\hline Fo [mm] & 7 \\
\hline Fo-direction of flow & $R \rightarrow L$ \\
\hline MPA [mm] & 13 \\
\hline Zs-BPD & +3.19 \\
\hline Zs-FL & +3.25 \\
\hline Zs-GA & +3.13 \\
\hline Ao [mm] & 7.73 \\
\hline Zs-BPD & +1.81 \\
\hline Zs-FL & +2.64 \\
\hline Zs-GA & +1.92 \\
\hline AoV v ${ }_{\text {max }}[\mathrm{cm} / \mathrm{s}]$ & 135.5 \\
\hline Aol v ${ }_{\text {max }}[\mathrm{cm} / \mathrm{s}]$ & 156.89 \\
\hline CVPS & $9 / 10$ \\
\hline
\end{tabular}

\section{Discussion}

The broad pulmonary trunk should draw special attention in the context of predicting the postnatal condition and the assessment of cardiopulmonary efficiency of newborns [1-2]. A dilated MPA in the three-vessel view could be found in isolated pulmonary valve stenosis with post-stenotic dilatation of the main pulmonary artery or in tetralogy of Fallot with absent pulmonary valve syndrome [3-8].

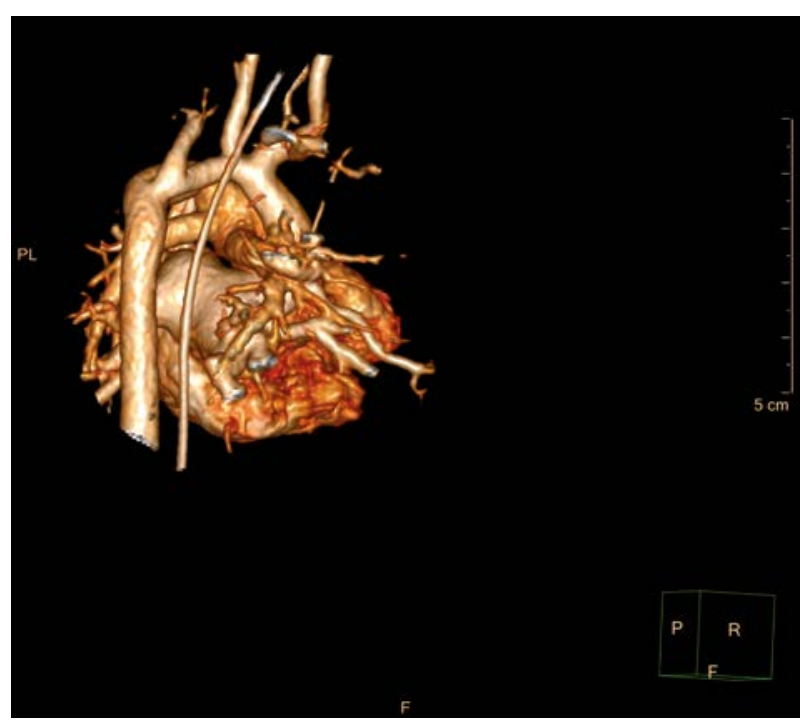

Figure 7. Angio(T, newborn: a picture of the coarctative nature of the isthmic segment (Aol $3 \mathrm{~mm}, \mathrm{v}_{\max } 245 \mathrm{~cm} / \mathrm{s}$ ) 
Table 2. Differential diagnosis in dilated main pulmonary artery (MPA)

\begin{tabular}{|c|c|}
\hline Dilated MPA in differential diagnosis & References \\
\hline Pulmonary valve stenosis with post-stenotic dilatation & $\begin{array}{l}\text { - A dilated MPA in the three-vessel-view with the turbulent antegrade flow could be found in isolated } \\
\text { pulmonary valve stenosis with post-stenotic dilatation of the main pulmonary artery [3-8, 31-32] }\end{array}$ \\
\hline $\begin{array}{l}\text { Tetralogy of Fallot with absent pulmonary } \\
\text { valve syndrome (APVS) }\end{array}$ & $\begin{array}{l}\text { - A dilated MPA in the three-vessel-view in tetralogy of Fallot with absent pulmonary valve syndrome } \\
\text { with to and fro blood flow and patterns of severe stenosis and insufficiency of the pulmonary valve } \\
\text { - Width of MPA does not correlate with the survival of the newborns with APVS, but affects the } \\
\text { respiratory tract compression and respiratory dysfunction, probably secondary to the pulmonary valve } \\
\text { regurgitation, seen prenatally [3-8,33-36] }\end{array}$ \\
\hline Ductal constriction & $\begin{array}{l}\text { - Constriction of fetal ductus arteriosus is a risk factor for pulmonary hypertension in the newborn } \\
\text { period with known severe consequences [37-42] }\end{array}$ \\
\hline $\begin{array}{l}\text { Pulmonary hypertension/congenital diaphragmatic } \\
\text { hernia (CDH), liver herniation (LV) }\end{array}$ & $\begin{array}{l}\text { - Larger MPA diameter best correlates with postnatal death and respiratory morbidity in CDH } \\
\text { - Fetal MPA diameters are probably related to the severity of pulmonary hypoplasia in CDH } \\
\text { - PA diameters appeared to be correlated with prognosis in infants with } \mathrm{CDH}+\mathrm{LH}[25,27,43,44]\end{array}$ \\
\hline Pulmonary hypertension/HLHS & $\begin{array}{l}\text { - Enlarged MPA in fetal hypoplastic left heart syndrome } \\
\text { - There were statistical differences between PA/A0 ratio at } 39 \text { weeks of gestation in pulmonary } \\
\text { hypertension and HLHS groups }[28,43]\end{array}$ \\
\hline Coarctation of the aorta-COA & - Fetuses whose PA/Ao is greater than 1.6 are more likely to suffer from CoA $[13,16]$ \\
\hline
\end{tabular}

Fetal heart disproportion in the cross section of four heart chambers and three vessels of the upper mediastinum in favour of the right side in the third trimester of a pregnancy may be the variant of the norm, but then coarctation of the aorta should be excluded [9-18].

In our case, coarctation of the aorta was suspected both preand postnatally due to the dominant picture of the accelerated flow velocities, with the maximum velocity AoI $=156-246 \mathrm{~cm} / \mathrm{s}$, but the patient did not require neonatal surgery. Based on retrospective review of the case we tried to explain our prenatal and early postnatal findings. The prenatal diagnosis of fetal CoA is still very challenging, and it remains one of the most difficult cardiac defects to diagnose before birth (Table 2). The positive diagnosis of the fetal CoA was accompanied by additional abnormalities, including LSVC, which could have the potential of impairing the left ventricular filling and imitated CoA.

With the presentation of the dilated MPA, smaller right pulmonary artery (RPA), left pulmonary artery (LPA), shorter time-to-peak velocity, absent end-diastolic flow, and increased pulsatility index in the pulmonary artery, the other possible explanation could be fetal increased pulmonary resistance as a base of the later neonatal hypertension. Different type of persistent pulmonary hypertension should be taken into differential diagnosis to speed up NO (nitric oxide) inhalation with magnesium treatment during the transition time in the first days after birth to avoid respiratory morbidity.

Accelerating flows through the ductus arteriosus, tricuspid valve dysplasia/dysfunction, higher spectrum of the fetal pulmonary vein downflow, extended atrial conduction time, could be presented in the course of transient occlusion of the ductus arteriosus and in utero infection [19-30]. So, after the exclusion of the structural congenital heart defects as a base of the dilatation of the main pulmonary artery, we should consider other pathophysiological mechanisms, and neonatologists should be aware of this abnormal finding (Table 2).

\section{Conclusions}

The case presented by us draws attention to the value of echocardiographic evaluation in the third trimester of gestation, to better forecast and plan the care of a newborn baby. In the case of a very large dilatation of the pulmonary trunk and mild abnormalities of the fetus' left heart, we have to take into account significant difficulties in the process of physiological adaptation of the newborn to ectopic life. Not every case of disproportion at the level of three vessels of the upper mediastinum in favour of the pulmonary trunk after birth gives the classic picture of aortic coarctation requiring surgical treatment.

\section{Conflict of interest}

The authors declare no conflict of interest.

\section{REFERENCES}

1. Okazaki T, Nakazawa N, Ogasawara Y, Shoji H, Shimizu T, Makino S, et al. Increase in fetal pulmonary artery diameters during late gestation is a predictor of outcome in congenital diaphragmatic hernia with liver herniation. J Pediatr Surg 2011; 46: 2254-2259.

2. Tada K, Yamada S, Kumazawa K, Takata M, Nakata T, Masuyama H, et al. Changes in the aortic and pulmonary diameters in a fetus with hypoplastic left heart syndrome. J Med Ultrason 2001; 30: 115.

3. Vinnals F, Heredia F, Giuliano A. The role of the three vessels and trachea view (3VT) in the diagnosis of congenital heart defects. Ultrasound Obstet Gynecol 2003; 22: 358-367.

4. Yagel S, Arbel R, Anteby EY. The three vessels and trachea view (3VT) in fetal cardiac scanning. Ultrasound Obstet Gynecol 2002; 20: 340-345.

5. Chaoui R, McEwing R. Three cross-sectional planes for fetal color Doppler echocardiography. Ultrasound Obstet Gynecol 2003; 21: 81-93.

6. Jeanty P, Chaoui R, Tihonenko I. A review of findings in fetal cardiac section drawings, part 3: the 3-vessel-trachea view and variants. J Ultrasound Med 2008; 27: 109-117.

7. Gardiner H, Chaoui R. The fetal three-vessel and tracheal view revisited. Semin Fetal Neonatal Med 2013; 18: 261-268.

8. Quarello E, Bault JP, Chaoui R. Prenatal three-vessel and tracheal view: abnormal features. Gynecol Obstet Fertil 2014; 42: 273-289. 
9. Brown DL. Borderline findings in fetal cardiac sonography. Semin Ultrasound CT MR 1998; 19: 329-335.

10. Brown DL, Durfee SM, Hornberger LK. Ventricular discrepancy as a sonographic sign of coarctation of the fetal aorta: how reliable is it? J Ultrasound Med 1997; 16: 95-99.

11. Haxel C, Patel S, Schuchardt E, Howley L, Bielby J, Gilbert L, et al. It's the angle: improved identification of fetal aortic coarctation. Ultrasound Obstet Gynecol 2019; 54 (Suppl. 1): 68.

12. Wang H, Lei W, Liu J, Yang B, Li H, Huang D. The diastolic and systolic velocity time integral ratio of aortic isthmus is a sensitive indicator of aortic coarctation in fetuses. Ultrasound Obstet Gynecol 2019; 54 (Suppl. 1): 42.

13. Qin JX, Min ZS. Application of Z-score combined with cardiovascular diameter ratio in fetal coarctation of the aorta. Ultrasound Obstet Gynecol 2019; 54 (Suppl. 1): 121.

14. Cattani L, Contro E, Balducci A, Prandstraller D, Perolo A, Farina A, et al. Predicting of neonatal coarctation of the aorta at fetal echocardiography: a scoring system. Ultrasound Obstet Gynecol 2019; 54 (Suppl. 1): 303.

15. Han J, Zhang L, Wu Q, Wang L, Wang J, Xuan Y, et al. The value of AO/ SVC ratio in the $3-\mathrm{V}$ view and $\mathrm{Y}$ sign appearance in the descending aorta coronary view in predicting fetus coarctation of aorta. Ultrasound Obstet Gynecol 2019; 54 (Suppl. 1): 306.

16. Słodki M, Rychik J, Moszura T, Janiak K, Respondek-Liberska M. Measurement of the great vessels in the mediastinum could help distinguish true from false-positive coarctation of the aorta in the third trimester. J Ultrasound Med 2009; 28: 1313-1317.

17. Jowett V, Aparicio P, Santhakumaran S, Seale A, Jicinska H, Gardiner HM. Sonographic predictors of surgery in fetal coarctation of the aorta. Ultrasound Obstet Gynecol 2012; 40: 7.

18. Sajnach-Menke M, Respondek-Liberska M. Is persistent left superior vena cava a benign finding? Analysis of 27 cases from fetal cardiology centre in Poland. Ultrasound Obstet Gynecol 2019; 54 (Suppl. 1): 136.

19. Machado MV, Chita SC, Allan LD. Acceleration time in the aorta and pulmonary artery measured by Doppler echocardiography in the midtrimester normal human fetus. Br Heart J 1987; 58: 15-18.

20. Hornung TS, Heads A, Hunter AS. Right ventricular dilatation in the fetus: a study of associated features and outcome. Pediatr Cardiol 2011;22: 215-217.

21. Pasquini L, Fichera A, Tan T, Ho SY, Gardiner H. Left superior caval vein: a powerful indicator of fetal coarctation. Heart 2005; 91: 539-540.

22. Respondek-Liberska M. Ocena przepływów krwi w naczyniach płuc w prenatalnym badaniu echokardiograficznym - znaczenie nieprawidłowych przepływów. W: Diagnostyka prenatalna. USG/ECHO. PZWL, Warszawa 2019.

23. Huhta J, Kalter C. Maternal hyperoxygenation for the treatment of fetal ductal occlusion with hydrops. Ultrasound Obstet Gynecol 2019; 54 (Suppl. 1): 160.

24. Fuloria M, Aschner JL, Persistent pulmonary hypertension of the newborn. Seminars in Fetal and Neonatal. 2017; 22: 220-226.

25. Ruano R, Aubry MC, Barthe B, Mitanchez D, Dumez Y, Benachi A. Predicting perinatal outcome in isolated congenital diaphragmatic hernia using fetal pulmonary artery diameters. J Pediatr Surg 2008; 43: 606-611.

26. Vulentin JF, Lim FY, Cnota J, Kline-Fath B, Salisbury S, Haberman B, et al. Prenatal pulmonary hypertension index: novel prenatal predictor of severe postnatal pulmonary artery hypertension in antenatally diagnosed congenital diaphragmatic hernia. J Pediatr Surg 2010; 45: 703-708.

27. Okazaki T, Nakazawa N, Ogasawara Y, Shoji H, Shimizu T, Makino S, et al. Increase in fetal pulmonary artery diameters during late gestation is a predictor of outcome in congenital diaphragmatic hernia with liver herniation. J Pediatr Surg 2011; 46: 2254-2259.

28. Tada K, Yamada S, Kumazawa K, Takata M, Nakata T, Masuyama H, et al. Changes in the aortic and pulmonary diameters in a fetus with hypoplastic left heart syndrome. J Med Ultrason 2001; 30: 115.

29. Gross BR, Cohen HL, Schlessel JS. Perinatal diagnosis of bilateral testicular torsion: beware of torsions simulating hydroceles. J Ultrasound Med 1993; 12: 479-481.
30. Pretorius DH, Halsted MJ, Abels W, Catanzarite VA, Kaplan G. Hydroceles identified prenatally: common physiologic phenomenon? J Ultrasound Med 1998;17: 49-52.

31. Todros T, Paladini D, Chiappa E, Russo MG, Gagliotti P, Pacileos G, et al. Pulmonary stenosis and atresia with intact ventricular septum during prenatal life. Ultrasound Obstet Gynecol 2003; 21: 228-233.

32. Płużańska J, Dryżek P, Moczulska H, Słodki M, Krekora M, Gulczyńska E, et al. Prenatal qualification for postnatal balloon valvuloplasty in isolated critical pulmonary valve stenosis based on 10 cases from tertriary centre of fetal cardiology. Prenat Cardio 2015; 5: 13-18.

33. Wen-Jun Z, Zhong-Lei Z, Jun-Jie C, Xiao-Yu S. Prenatal ultrasonic diagnosis of absent pulmonary valve syndrome. Medicine (Baltimore) 2017; 96: e7747.

34. Talwar S, Divya A, Choudhary SK, Kumar Gupta S, Ramakriahnan S, Kothari SS, et al. Mid-term results of correction of tetralogy of Fallot with absent pulmonary valve. Indian Heart J 2017; 69: 767-771.

35. Gottschalk JC, Jehle C, Herberg U, Breuer J, Brockmeier K, Bennink G, et al. Prenatal diagnosis of absent pulmonary valve syndrome from first trimester onwards: novel insights into pathophysiology, associated conditions and outcome. Ultrasound Obstet Gynecol 2017; 49: 637-642.

36. Zych-Krekora K, Krekora M, Kopala M, Respondek-Liberska M. Absent pulmonary valve syndrome-special prenatal care and early surgery in obstetric/cardiac center - a new hope for postnatal survivors? Prenat Cardio 2017; 7: 19-25.

37. Jaillard S, Elbaz F, Bresson-Just S, Riou Y, Houfflin-Debarge V, Rakaza T. Pulmonary vasodilator effects of norepinephrine during the development of chronic pulmonary hypertension in neonatal lambs. Br J Anaesth 2004; 93: 818-824.

38. Larrue B, Jaillard S, Lorthior M, Roubliova X, Butrous G, Rakza T. Pulmonary vascular effects of sildenafil on the development of chronic pulmonary hypertension in the ovine fetus. Am J Physiol Lung Cell Mol Physiol 2005; 288: L1193-L1200.

39. Zenker M, Klinge J, Kruger C, Singer H, Scharf J. Severe pulmonary hypertension in a neonate caused by premature closure of the ductus arteriosus following maternal treatment with diclofenac: a case report. J Perinat Med 1998; 26: 231-234.

40. Talati AJ, Salim MA, Korones SB. Persistent pulmonary hypertension after maternal naproxen ingestion in a term newborn: a case report. Am J Perinatol 2000; 17: 69-71.

41. Van Marter LJ, Leviton A, Allred EN, Pagano M, Sullivan KF, Cohen A. Persistent pulmonary hypertension of the newborn and smoking and aspirin and nonsteroidal anti-inflammatory drug consumption during pregnancy. Pediatrics 1996; 97: 658-663.

42. Gewillig M, Brown SC, De Catte L, Debeer A, Eyskens B, Cossey V. Premature foetal closure of the arterial duct: clinical presentations and outcome. Eur Heart J 2009; 30: 1530-1536.

43. Romanowicz H, Czichos E, Zych-Krekora K, Krekora M, Słodki M, Respondek-Liberska M. Retrospective analysis of prenatal echocardiography findings in cases of congenital heart defects: comparison with postnatal pulmonary hypertension revealed by lungs histopathology (2010-2015). Prenat Cardio 2015; 5: 12-18.

44. Sokol J, Bohn D, Lacro RV, Ryan G, Stephens D, Rabinovitch M, et al. Fetal pulmonary artery diameters and their association with lung hypoplasia and postnatal outcome in congenital diaphragmatic hernia. Am J Gynecol 2002; 186: 1085-1090

Division of work

Julia Murlewska (ORCID: 0000-0002-8266-4585): research concept and design, data analysis and interpretation, writing the article

Joanna Pekasiewicz (ORCID: 0000-0002-9812-1753): collection and/or assembly of data, data analysis and interpretation

Maria Respondek-Liberska (ORCID: 0000-0003-0238-2172): data analysis and interpretation, critical revision of the article, final approval of article 